\title{
The importance of serum neutrophil gelatinase- associated lipocalin level in patients with lupus nephritis
}

\author{
Mohammad Reza Jafari Nakhjavani ${ }^{1}{ }^{\complement}$, Sima Abediazar ${ }^{*}{ }^{\circledR}$, Amir Ghorbanihaghjo $^{3}$, Behnaz \\ Hanafizadeh $^{1}$, Sepideh Zununi Vahed ${ }^{2}$, Tala Pourlak ${ }^{1,2}$ \\ ${ }^{1}$ Department of Rheumatology, Connective Tissue Diseases Research Center, Tabriz University of Medical Sciences, Tabriz, Iran \\ ${ }^{2}$ Kidney Research Center, Tabriz University of Medical Sciences, Tabriz, Iran \\ ${ }^{3}$ Biotechnology Research Center, Tabriz University of Medical Sciences, Tabriz, Iran
}

\section{A R T I C L E I N F O}

Article Type:

Original

\section{Article History:}

Received: 12 November 2018

Accepted: 2 January 2019

Published online: 26 January 2019

\section{Keywords:}

Systemic lupus erythematosus,

Biomarker, Lupus nephritis,

End-stage renal disease,

Chronic kidney diseases,

Neutrophil gelatinase-

associated lipocalin,

\begin{abstract}
A B S T RA C T
Introduction: The neutrophil gelatinase-associated lipocalin (NGAL) has emerged as a biomarker of renal damage.

Objectives: The aim of this study was to assess the serum levels of NGAL (sNGAL) as a marker of disease activity in individuals with lupus nephritis (LN).

Patients and Methods: This study contained 50 systemic lupus erythematosus (SLE) individuals with $(\mathrm{n}=25)$ and without $(\mathrm{n}=25)$ nephritis, and 39 healthy controls. The sNGAL levels were measured by ELISA. Renal function test, urinary parameters, lupus serology activity, and also calculated SLE disease activity index (SLEDAI) were analyzed to determine their associations with sNGAL.

Results: The results revealed that the SLE individuals with or without nephritis had a raised serum NGAL levels as compared to control subjects $(P<0.001)$. Additionally, sNGAL levels in LN individuals were meaningfully higher compared to those in non-LN patients $(P<0.001)$. Serum NGAL showed a significant correlation with the SLEDAI, serum creatinine, and $24-\mathrm{h}$ urinary protein $(P<0.05)$. More importantly, sNGAL had a significant positive correlation with the activity index of $\mathrm{LN}(r=0.616, P=0.001)$. In the ROC curve analysis, the measurement of sNGAL level showed a good diagnostic performance for distinguishing individuals with LN from SLE patients without renal involvement with AUC $=0.902(P<0.001), 72 \%$ sensitivity, and $99 \%$ specificity. Moreover, sNGAL could identify all of SLE patients from controls with high accuracy, AUC $=0.99, P<0.001$, with $99 \%$ sensitivity, and $97 \%$ specificity.

Conclusion: Serum NGAL had an association with clinical parameters and could discriminate LN from SLE patients without renal involvement. Our result suggests that serum NGAL can be used for early diagnosis of LN and identifying active LN
\end{abstract}

Implication for health policy/practice/research/medical education:

The knowledge of LN activity and the disease condition presents significant role in the treatment and prognosis of lupus patients. In the present study, we evaluated the diagnostic values of serum NGAL in serum samples of lupus patients with and without nephritis and healthy controls. In summary, the increased urinary NGAL but not its serum levels have been confirmed as a predictor of renal involvement in SLE and LN activity. We found that serum NGAL can also be a useful biomarker for the identification of renal involvement in SLE patients, LN activity and the discrimination of LN among SLE patients. Further studies should be conducted to support the results.

Please cite this paper as: Jafari Nakhjavani MR, Abediazar S, Ghorbanihaghjo A, Hanafizadeh B, Zununi Vahed S, Pourlak T. The importance of serum neutrophil gelatinase-associated lipocalin level in patients with lupus nephritis. J Renal Inj Prev. 2019;8(2):133-139. doi: 10.15171/jrip.2019.25.

\section{Introduction}

Systemic lupus erythematosus (SLE) is a chronic inflammatory autoimmune disease with several clinical manifestations. Lupus nephritis (LN) is a serious renal involvement in SLE and is more prevalent in blacks and
Asians in comparison to other races (1). Within 15 years after diagnosis, LN patients (10\%-30\%) progress the endstage renal disease (ESRD) (2).

Renal biopsy is a useful tool for diagnosis, prognosis, and monitoring therapy of LN. Yet, it is an inconvenient 
and invasive process, thus, the American College of Rheumatology (ACR) criteria is applied to diagnose LN (3) using the quantity of 24 -h urinary protein. This test has also often resulted in inaccurate results. Additionally, the urine sediment, glomerular filtration rate (GFR), and complement components (like C3 and C4) are considered to be too inaccurate to differentiate the acute inflammatory and the chronic degenerative changes (4). Thus, alternative accurate biomarkers have been required for LN diagnosis or monitoring (5). Presently, numerous studies have been carried out to discover potential biomarkers including urinary monocyte chemoattractant protein-1 (uMCP-1)(6), transforming growth factor beta 1 (uTGF- $\beta 1$ ), clusterin (7), and interleukin-17 (uIL-17). Neutrophil gelatinase-associated lipocalin (NGAL), an iron-transporting protein (8), is a predictor of the acute kidney injury (AKI) while it has also been related to the LN.

As an innate antimicrobial agent, NGAL was originally identified in activated neutrophils $(9,10)$. Following ischemia, nephrotoxic, or AKI, NGAL is expressed and accumulated in the kidney tubules and urine (11) in both animal models and humans $(12,13)$. Moreover, it may be involved in the pathophysiology of chronic renal failure such as chronic glomerulonephritis and polycystic kidney disease (14). NGAL is correlated with GFR and tubular atrophy(15) and its high levels in serum/plasma and urine have been observed in patients with $\operatorname{SLE}(4,16)$, diabetic nephropathy (17), IgA nephropathy (18), and nephrotic syndrome (19).

In a mouse model of LN, NGAL level in the kidney, urine, and serum is elevated in connection with disease severity (20). Likewise, human studies have displayed that urinary NGAL (uNGAL) levels can reflect the decline of renal function and the disease activity in LN (5,2130). Furthermore, it may predict poor response after induction therapy (31). However, the value of serum NGAL (sNGAL) as a predictor of renal flare is less clear because of contradictory results.

\section{Objectives}

The aim of our study was to investigate the association of serum NGAL with renal involvement and LN activity in SLE patients with and without nephritis.

\section{Patients and Methods}

\section{Patients' selection}

A cross-sectional study was conducted in Imam Reza hospital, Tabriz, Iran and included 50 SLE patients with and without nephritis. Patients suffering from any of the following conditions were excluded; active infection at the time of sampling, diabetes mellitus, history of HIV and hepatitis C virus, patients with other type of glomerulopathy, overlap syndrome, malignancies, urinary tract infection, and those with ESRD undergoing hemodialysis or renal replacement therapy. All samples were collected from September 2016 to June 2018. Disease activity was determined by the SLE disease activity index (SLEDAI) (32), the disease was considered active when the SLEDAI score was $\geq 6$.

\section{Clinical and laboratory measurement}

For each patient, fresh blood sample was collected. Serum samples were frozen within 2 hours after collection and stored at $-8^{\circ} \mathrm{C}$ until further analysis. Serum creatinine levels, serum chemistry, complement (C3 and C4), 24-h urinary protein, antinuclear antibodies (ANA), and antidsDNA antibody (anti-dsDNA) were analyzed. NGAL levels were assessed by enzyme-linked immunosorbent assay (ELISA) benefitting a commercially available kit (ZellBio GmbH, Cat No: ZB-11719c-H9648, Germany) following the manufacturer's instructions. All measurements were conducted in triplicate. On the day of the sampling, information about patient demographic characteristics, medications, and disease activity was recorded.

\section{Ethical issues}

The protocol of the study was institutionally approved by the Clinical Research Ethics Committee of the Tabriz University of Medical Sciences, Tabriz, Iran (\# IR.TBZMED.REC.1396.598) and has therefore been performed in accordance with the ethical standards laid down in the 1964 Declaration of Helsinki and its later amendments. The protocol of the study was clarified to all participants and written informed consent was achieved from the patients. This study was extracted from Behnaz Hanafizadeh residency thesis in Tabriz University of Medical Sciences, Tabriz, Iran (Thesis\# 58580).

\section{Statistical analysis}

Data were given as mean \pm SD for normally or median with interquartile range (IQR) for non-parametric distributed variables. Categorical variables were compared by Chi-square test. For parametric and nonparametric data, the differences between groups were analyzed by the student's t test or ANOVA and Mann-Whitney U or Kruskal-Wallis tests, respectively. Spearman's correlation coefficient was used to test correlations between sNGAL and other variables. Areas under ROC curves (AUC) and 95\% confidence intervals (CI) were calculated. Statistical analysis was performed using SPSS statistical software, version 16.0 (SPSS, Chicago, IL). $P$ values less than 0.05 was considered significant.

\section{Results}

This study comprised 50 individuals with SLE, 10 males and 40 females, with a mean age of $36.7 \pm 11$ years old. The individuals were divided into three groups: group 1; 25 SLE individuals without nephritis and group 2; 25 SLE 
individuals with biopsy-proven LN. Group 3 included 39 age/gender matched healthy subjects with a mean age of $38.4 \pm 9.7$ years old and considered as controls. The mean age of onset of LN was $35.4 \pm 11.7$ years old and their disease diagnosed at the time of sampling. The severity of lupus was evaluated among the patients. Eighty-eight percent of patients had an active disease (SLEDAI scores $\geq 6$ ), the median (IQR) score of LN patients was 10 (814) versus SLE without nephritis 6 (5.5 to 9). As expected, all patients with LN had significantly higher levels of proteinuria (Median [IGR] of 1368 [926 to 2000] versus 125 [92-170]), lower levels of the complement, and $40 \%$ of them had hematuria $(n=10)$ (Table 1). However, in terms of mean age and gender no significant differences were observed $(P>0.05)$.

Twenty-two LN cases (92\%) had active disease (rSLEDAI $\geq 8$ ). Cases had normal serum creatinine levels. Twentysix SLE patients (52\%) had inflammatory arthritis, 52\% of the cases had rash, and eight (16\%) had a prevalence of serositis. Some of SLE patients had leucopenia (24\%), hematuria (20\%), and thrombocytopenia (12\%). Moreover, five cases (10\%) had central nervous system (CNS) involvement. The results showed that the incidence of hematuria and rash in the two groups was significantly different.

Our results showed that the SLE group (with or without
LN) had a higher level of sNGAL as compared to controls with mean of $105 \pm 15.9$ versus $52 \pm 14.3 \mathrm{ng} / \mathrm{mL}(P<0.001$; Figure 1A). Additionally, level of sNGAL meaningfully enhanced in cases with $\mathrm{LN}$ as compared to those without $\mathrm{LN}$, with mean of $115.67 \pm 11.92 \mathrm{ng} / \mathrm{mL}$ and $94.33 \pm 11.75$ $\mathrm{ng} / \mathrm{mL}$, respectively $(P<0001$; Figure $1 \mathrm{~B})$. In patients who had CNS, skin, and kidney involvement, significantly raised values of serum NGAL were observed $(P<0.003$; Table 2).

In the LN group, significantly positive correlations were detected between sNGAL $(\mathrm{ng} / \mathrm{mL})$ and SLEDAI $(\mathrm{r}=$ $0.427, P=0.033)$ and anti-dsDNA $(\mathrm{r}=0.487, P=0.014)$. Moreover, there was a strong positive correlation between serum NGAL levels and renal parameters such as 24 hours urinary proteins $(r=0.793)$, serum creatinine $(r=0.756)$, and LN activity index $(\mathrm{r}=0.616),(P<0.001)$. Likewise, in SLE patients without LN, significant correlations were found between sNGAL and SLEDAI $(r=0.450, P=0.024)$, and proteinuria $(r=0.453, P=0.023)$ (Figures $2 \mathrm{C}$ and $\mathrm{D}$ ).

Moreover, there were correlations between sNGAL and other clinical variables in SLE patients with and without LN, however, they were not statistically significant. Additionally, correlations between sNGAL and clinical manifestations of the cases are listed in Table 3.

The ROC curve for sNGAL was calculated to discriminate SLE cases from healthy controls and also SLE

Table 1. Demographic and baseline clinical data

\begin{tabular}{|c|c|c|c|c|}
\hline Characteristics/Groups & Total SLE patients & SLE without LN & SLE with LN & $P$ Value $^{\mathrm{a}}$ \\
\hline \multicolumn{5}{|c|}{ Demographic characteristics } \\
\hline No. of cases & 50 & 25 & 25 & \\
\hline $\begin{array}{l}\text { Gender, No. (\%) } \\
\text { Male } \\
\text { Female }\end{array}$ & $\begin{array}{l}10(20) \\
40(80)\end{array}$ & $\begin{array}{c}5(20) \\
20(80)\end{array}$ & $\begin{array}{c}5(20) \\
20(80)\end{array}$ & 1 \\
\hline Age, mean \pm SD $(y)$ & $36.7 \pm 11.3$ & $38 \pm 10.9$ & $35.4 \pm 11.7$ & 0.429 \\
\hline \multicolumn{5}{|l|}{ Biomarkers } \\
\hline C3 (mg/dL) & $47.3 \pm 31.27$ & $72.28 \pm 24.0$ & $22.32 \pm 10.98$ & $<0.001$ \\
\hline $\mathrm{C} 4(\mathrm{mg} / \mathrm{dL})^{\mathrm{b}}$ & 8.5 (7 to 10$)$ & $9(8$ to 10$)$ & 6 to 10$) 8($ & 0.136 \\
\hline Anti-dsDNA ${ }^{b}$ & 11.5 (8 to 17.75$)$ & $9(8$ to 11$)$ & 16 (12 to 43 ) & 0.002 \\
\hline Creatinine & $1.09 \pm 0.21$ & $0.87 \pm 0.10$ & $1.14 \pm 0.22$ & $<0.001$ \\
\hline Proteinuria $(\mathrm{mg} / 24 \mathrm{~h})^{\mathrm{b}}$ & 375 (123.75 to 1401$)$ & 125 (92 to 170$)$ & 1368 (926 to 2000$)$ & $<0.001$ \\
\hline SLEDAI ${ }^{\text {b }}$ & $8(6$ to 10.5$)$ & 6 (5.5 to 9) & 10 (8 to 14$)$ & 0.001 \\
\hline Activity index $\pm S D$ & - & - & $10.8 \pm 3.0$ & - \\
\hline Chronicity index ${ }^{b}$ & - & - & $2(2$ to 4$)$ & - \\
\hline \multicolumn{5}{|c|}{ Systemic organ involvements, No. (\%) } \\
\hline Serositis & $8(16)$ & $3(12)$ & $5(20)$ & 0.70 \\
\hline CNS involvement & $5(10)$ & $1(4)$ & $4(16)$ & 0.35 \\
\hline Rash & $26(52)$ & $20(80)$ & $6(24)$ & $<0.001$ \\
\hline Arteritis & $26(52)$ & $16(64)$ & $15(60)$ & 0.15 \\
\hline Hematuria & $10(20)$ & $0(0)$ & $10(40)$ & 0.001 \\
\hline Leucopenia & $12(24)$ & $6(24)$ & $6(24)$ & 1 \\
\hline Thrombocytopenia & $6(12)$ & $4(16)$ & $2(8)$ & 0.66 \\
\hline
\end{tabular}

Abbreviations: Anti-dsDNA: anti-double strand DNA, SLE: systemic lupus erythematosus, SLEDAI: systemic lupus erythematosus disease activity index. The quantity data are expressed as mean \pm SD.

aupus nephritis versus non-lupus nephritis.

bMedian, Interquartile Range (IRQ). 

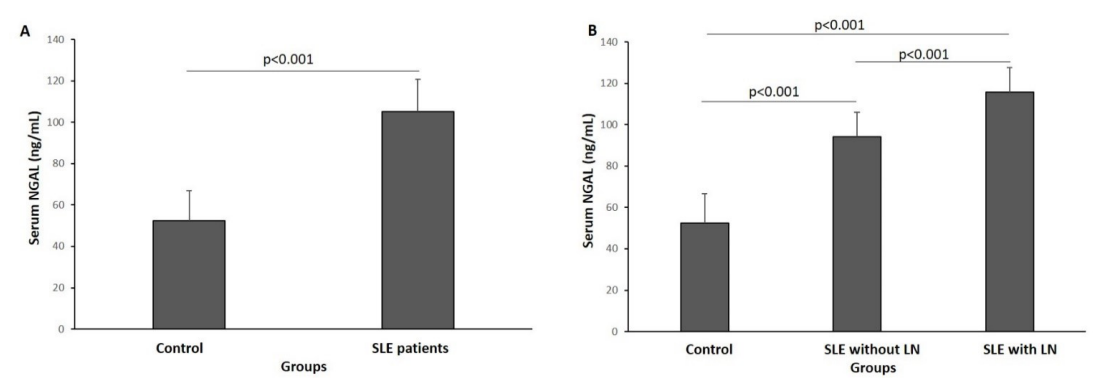

Figure 1. Serum level of NGAL in the studied groups. (A) Serum levels of NGAL between healthy controls and SLE patients and (B) between SLE patients with and without nephritis. Values are mean \pm standard deviation. NGAL: neutrophil gelatinase associated lipocalin.

patients with LN from those with non-renal flare (Figure 3). The diagnostic performance of sNGAL presented that with high sensitivity (99\%) and specificity (97\%), sNGAL could discriminate SLE patients from healthy controls

Table 2. Serum levels of NGAL based on organ involvement in SLE patients $(\mathrm{N}=50)$

\begin{tabular}{lccc}
\hline Organs & Not-involved & Involved & $P$ value \\
\hline CNS & $102.83 \pm 15.0$ & $124.56 \pm 9.02$ & 0.003 \\
Skin & $111.67 \pm 15.73$ & $98.84 \pm 13.66$ & 0.003 \\
Arteritis & $107.74 \pm 15.94$ & $102.47 \pm 15.77$ & 0.246 \\
Leucopenia & $104.46 \pm 16.50$ & $106.71 \pm 14.42$ & 0.674 \\
Serositis & $103.94 \pm 15.6$ & $110.55 \pm 17.22$ & 0.278 \\
\hline Thrombocytopenia & $105.33 \pm 16.02$ & $102.58 \pm 16.33$ & 0.696 \\
\hline Kidney & $94.33 \pm 11.75$ & $115.67 \pm 11.92$ & $<0.001$ \\
\hline
\end{tabular}

CNS: Central nervous system, SLE: Systemic lupus erythematosus.

The quantity data are expressed as mean \pm SD. with a cutoff of $72.95 \mathrm{ng} / \mathrm{mL}$ and $\mathrm{AUC}=0.99(P<0.001)$ (Figure $3 \mathrm{~A}$ and $\mathrm{B}$ ). Moreover, diagnostic reliability study in the present study detected a good efficacy for sNGAL to distinguish SLE individuals with nephritis from those without nephritis with the best cutoff of 111.6 (AUC= 0.90) $(P<0.001)$, sensitivity $=72 \%$, and specificity $=99 \%$ (Figure $3 \mathrm{C}$ and $\mathrm{D}$ ).

\section{Discussion}

In the current investigation, we studied the NGAL and traditional measures of LN in serum samples of SLE patients. We found that the serum NGAL was significantly higher in SLE individuals in comparison to the control subjects. Furthermore, sNGAL was even more elevated in SLE patients with LN when compared to those without nephritis. Additionally, individual sera biomarker was related to histologic findings in $\mathrm{LN}$, especially those representing LN activity.

Table 3. Association between serum NGAL $(\mathrm{ng} / \mathrm{mL})$ and various parameters in the SLE patients

\begin{tabular}{|c|c|c|c|c|}
\hline \multirow{2}{*}{ Variable } & \multicolumn{2}{|c|}{ SLE patients without nephritis } & \multicolumn{2}{|c|}{ SLE patients with nephritis } \\
\hline & Spearman's rho & $P$ value & Spearman's rho & $P$ value \\
\hline Age & -0.143 & 0.496 & 0.239 & 0.251 \\
\hline Gender & 0.028 & 0.895 & -0.055 & 0.792 \\
\hline SLEDAI & 0.450 & 0.024 & 0.427 & 0.033 \\
\hline Proteinuria & 0.453 & 0.023 & 0.793 & $<0.001$ \\
\hline Hematuria & - & - & 0.289 & 0.161 \\
\hline $\mathrm{C} 3$ & -0.007 & 0.974 & -0.190 & 0.362 \\
\hline $\mathrm{C} 4$ & 0.052 & 0.804 & -0.084 & 0.688 \\
\hline ANA & -0.297 & 0.149 & 0.227 & 0.276 \\
\hline anti-dsDNA & -0.279 & 0.177 & 0.487 & 0.014 \\
\hline Activity index & - & - & 0.616 & 0.001 \\
\hline Chronicity index & - & - & 0.311 & 0.130 \\
\hline Creatinine & 0.10 & 0.633 & 0.756 & $<0.001$ \\
\hline CNS & 0.340 & 0.097 & 0.492 & 0.012 \\
\hline Rush & 0.097 & 0.644 & -0.234 & 0.261 \\
\hline Arteritis & 0.127 & 0.545 & 0.0 & 1 \\
\hline Leucopenia & 0.104 & 0.621 & 0.013 & 0.951 \\
\hline Serositis & -0.085 & 0.685 & 0.277 & 0.179 \\
\hline Thrombocytopenia & 0.136 & 0.516 & -0.061 & 0.771 \\
\hline
\end{tabular}

r: Spearman's rho correlation coefficient; anti-dsDNA: anti-double-stranded DNA; SLEDAI: systemic lupus erythematosus disease activity index; CNS, central nervous system. 

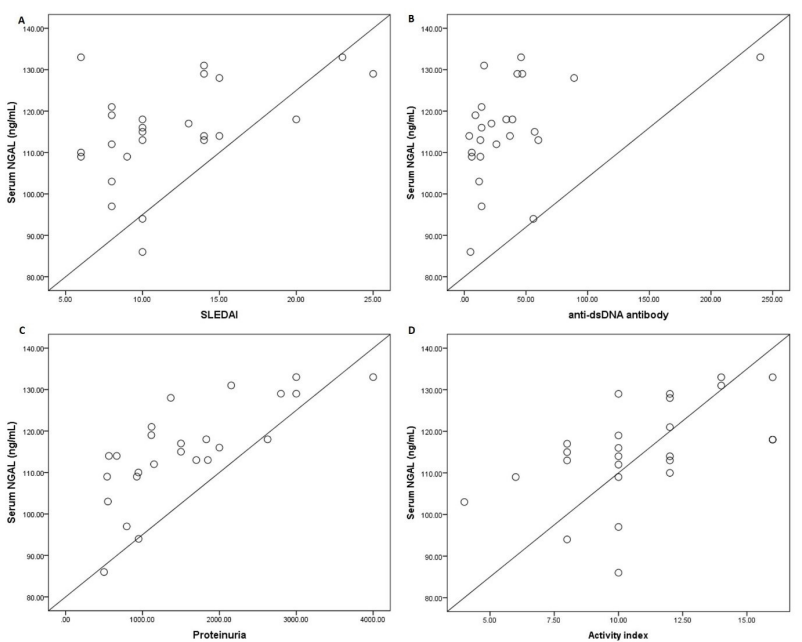

Figure 2. Correlation of serum NGAL with clinical parameters. Correlation between serum NGAL and (A) SLEDAI, (B) anti-double strand DNA antibodies, (C) proteinuria, and (D) LN activity index in SLE patients with nephritis.

The biologic function of NGAL is under active investigation (20). Pawar et al concluded that renal binding of pathogenic antibodies induces expression of NGAL. Increased level of NGAL has a critical role in the pathogenesis of nephritis through the promotion of inflammatory gene expression and apoptosis in kidney cells both in vitro and in vivo (20). NGAL is a predictive and early urinary marker that is induced rapidly by active inflammation in LN and declined with therapy (16). Data indicated that high uNGAL levels reflect the activity and severity of kidney disease in SLE patients $(4,16,21,27,28$, $33,34)$.

Our result of enhanced serum values of NGAL in LN is in line with those reported in the literature; however, their results were not statistically significant $(24,27,28,35)$. This may be due to different sample sizes. NGAL has been demonstrated as a marker of renal damage in LN $(4,29)$, which may explain why our patients with a history of biopsy-proven LN had higher serum NGAL levels. In contrast with these studies, Smith et al could not find a significant change in UNGAL levels between patients with active $\mathrm{LN}$ and those with non-LN in two international juvenile-onset SLE cohorts (25). Moreover, Kiani et al could not detect a relationship between UNGAL and LN in adult SLE patients (36). These results can be clarified by differences in the sampling time and the outcome measures used. These remarks suggest that NGAL needs further examination to be considered as a urine or serum biomarker to predict nephritis occurrence.

Regarding the connotation between kidney functions and NGAL, our investigation disclosed a meaningful positive association between sNGAL and each of 24 hours of urine protein, serum creatinine, anti-dsDNA antibodies, and activity index of LN. Although ANA and complement are generally used as the indicators of kidney
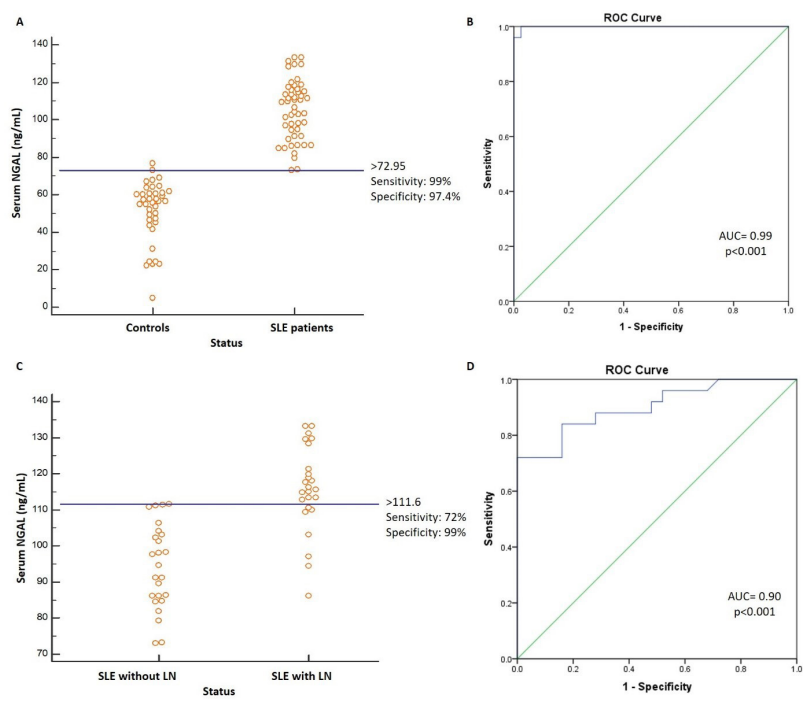

Figure 3. Receiver operating characteristic curves of serum NGAL. Graph ROC curves analysis showing AUC of serum NGAL to discriminate (A, B) SLE patients from healthy controls and ( $C$ and D) SLE patients with LN from those without LN. AUC: Area under the Curve, NGAL: neutrophil gelatinase associated lipocalin.

disease activity in the clinic, the present study did not find a statistically significant association between sNGAL and these clinical parameters. Our results are in line with the study of Pitashny et al (34) who showed a highly significant association between a renal parameter of SLEDAI score. However, they could not find an association between the complement or anti-dsDNA antibodies and UNGAL levels in adult patients.

Recently, a meta-analysis performed on fourteen studies has confirmed that UNGAL relatively has reasonable sensitivity and specificity in identifying LN and approximating LN activity, and also guessing kidney flares. The result suggests that UNGAL is a possible biomarker in monitoring LN activity and diagnosing LN with a pooled sensitivity of $73.6 \%$ and specificity of $78.1 \%$ (26). Brunner et al indicated that the measurement of NGAL together with GFR and MCP-1 was an admirable diagnostic tool for LN chronicity with AUC $=0.83$ (37). Likewise, we found that serum NGAL could also discriminate LN patients from SLE patients without nephritis with high accuracy (AUC $=0.902), 72 \%$ sensitivity, and 99\% specificity. Our result suggests that serum NGAL can be also used for early diagnosis of LN and identifying active LN.

Generally, it is approved that besides being the most hopeful next-generation biomarker in clinical nephrology, NGAL stimulates the growth and differentiation of kidney tubular epithelial cell in reply to ischemic injuries (38). Currently, in spite of some progressive research, the biological importance of NGAL needs further examination in nephrology.

Conclusion

In summary, the increased urinary NGAL but not its 
serum levels have been confirmed as a predictor of kidney involvement in SLE and LN activity. We found that serum NGAL can also be a useful biomarker for the identification of renal involvement in SLE patients and LN activity and the discrimination of LN among SLE patients. Further studies should be conducted to support the results.

\section{Study limitations}

We suppose that the small sample size of our studied groups was not adequate. Hence, further longitudinal larger scale studies are suggested to confirm the diagnostic value of serum NGAL in LN.

\section{Authors' contribution}

MRN and SA designed the study and selected the cases. $\mathrm{BH}$ did sampling. AGH performed experimental analysis and interpretation of the data. SZV prepared the draft. All authors read and signed the final paper.

\section{Conflicts of interest}

The authors declared no potential conflicts of interest with respect to the research, authorship, and/or publication of this article.

\section{Ethical considerations}

Ethical issues (including plagiarism, data fabrication, double publication) have been completely observed by the authors.

\section{Funding/Support}

This research was funded by the Connective Tissue Diseases Research Center of Tabriz University of Medical Sciences, Tabriz, Iran (Grant \# 5/D/577304).

\section{References}

1. Longo DL. La práctica de la medicina clínica. Cap. 1 En: DL Longo, DL Kasper, JL Jameson, AS Fauci, SL Hauser y J. Loscalzo (Eds.) Harrison Principios de Medicina Interna. México: McGraw-Hill-Interamericana. 2012;1596-1611.

2. Avihingsanon Y, Hirankarn N. Major lupus organ involvement: severe lupus nephritis. Lupus. 2010;19:13918. doi: 10.1177/0961203310376522.

3. Dooley MA. Clinical and laboratory features of lupus nephritis, Wallace DJ, Hahn BH. Dubois' Lupus Erythematosus7th ed. Philadelphia: Lippincott Williams \& Wilkins. 2007;1112-30.

4. Brunner HI, Mueller M, Rutherford C, Passo MH, Witte D, Grom A, et al. Urinary neutrophil gelatinase-associated lipocalin as a biomarker of nephritis in childhoodonset systemic lupus erythematosus. Arthritis Rheum. 2006;54:2577-84. doi: 10.1002/art.22008.

5. Susianti $\mathrm{H}$, Iriane $\mathrm{VM}$, Dharmanata $\mathrm{S}$, Handono $\mathrm{K}$, Widijanti A, Gunawan A, et al. Analysis of urinary TGFbeta1, MCP-1, NGAL, and IL-17 as biomarkers for lupus nephritis. Pathophysiology. 2015;22:65-71. doi: 10.1016/j. pathophys.2014.12.003.

6. Brunner HI, Bennett MR, Mina R, Suzuki M, Petri M, Kiani AN, et al. Association of noninvasively measured renal protein biomarkers with histologic features of lupus nephritis. Arthritis Rheum. 2012;64:2687-97. doi: 10.1002/ art.34426.

7. Wu CY, Yang HY, Chien HP, Tseng MH, Huang JL. Urinary clusterin-a novel urinary biomarker associated with pediatric lupus renal histopathologic features and renal survival. Pediatr Nephrol. 2018;33:1189-1198. doi: 10.1007/ s00467-018-3924-4.

8. Mao S, Jiang T, Shang G, Wu Z, Zhang N. Increased expression of neutrophil gelatinase-associated lipocalin receptor by interleukin-1beta in human mesangial cells via MAPK/ERK activation. Int J Mol Med. 2011;27:555-60. doi: 10.3892/ijmm.2011.613.

9. Goetz DH, Holmes MA, Borregaard N, Bluhm ME, Raymond KN, Strong RK. The neutrophil lipocalin NGAL is a bacteriostatic agent that interferes with siderophoremediated iron acquisition. Mol Cell. 2002;10:1033-43.

10. Kjeldsen L, Johnsen AH, Sengeløv H, Borregaard N. Isolation and primary structure of NGAL, a novel protein associated with human neutrophil gelatinase. J Biol Chem. 1993;268:10425-32.

11. Mishra J, Ma Q, Prada A, Mitsnefes M, Zahedi K, Yang J, et al. Identification of neutrophil gelatinase-associated lipocalin as a novel early urinary biomarker for ischemic renal injury. J Am Soc Nephrol. 2003;14:2534-43.

12. Supavekin S, Zhang W, Kucherlapati R, Kaskel FJ, Moore LC, Devarajan P. Devarajan, Differential gene expression following early renal ischemia/reperfusion. Kidney Int. 2003;63:1714-24. doi: 10.1046/j.1523-1755.2003.00928.x.

13. Mishra J, Dent C, Tarabishi R, Mitsnefes MM, Ma Q, Kelly C, et al. Neutrophil gelatinase-associated lipocalin (NGAL) as a biomarker for acute renal injury after cardiac surgery. Lancet. 2005;365:1231-8. doi: 10.1016/s01406736(05)74811-x.

14. Bolignano D, Donato V, Coppolino G, Campo S, Buemi A, Lacquaniti A, et al. Neutrophil gelatinase-associated lipocalin (NGAL) as a marker of kidney damage. Am J Kidney Dis. 2008;52:595-605. doi: 10.1053/j. ajkd.2008.01.020.

15. Bolignano D, Lacquaniti A, Coppolino G, Donato V, Campo S, Fazio MR, et al. Neutrophil gelatinase-associated lipocalin (NGAL) and progression of chronic kidney disease. Clin J Am Soc Nephrol. 2009;4:337-44. doi: 10.2215/cjn.03530708.

16. Hinze $\mathrm{CH}$, Suzuki M, Klein-Gitelman M, Passo MH, Olson J, Singer NG, et al. Neutrophil gelatinase-associated lipocalin is a predictor of the course of global and renal childhood-onset systemic lupus erythematosus disease activity. Arthritis Rheum. 2009;60:2772-81. doi: 10.1002/ art.24751.

17. Kim SY, Jeong TD, Lee W, Chun S, Sunwoo S, Kim SB, et al. Plasma Neutrophil Gelatinase-Associated Lipocalin as a Marker of Tubular Damage in Diabetic Nephropathy. Ann Lab Med. 2018;38:524-529. doi: 10.3343/alm.2018.38.6.524.

18. Ding H, He Y, Li K, Yang J, Li X, Lu R, et al. Urinary neutrophil gelatinase-associated lipocalin (NGAL) is an early biomarker for renal tubulointerstitial injury in IgA nephropathy. Clin Immunol. 2007;123L227-34.

19. Bolignano D, Coppolino G, Campo S, Aloisi C, Nicocia G, Frisina N, et al. Urinary neutrophil gelatinase-associated lipocalin (NGAL) is associated with severity of renal disease in proteinuric patients. Nephrol Dial Transplant. 
2008;23:414-6. doi: 10.1093/ndt/gfm541.

20. Pawar RD, Pitashny M, Gindea S, Tieng AT, Levine B, Goilav B, et al. Neutrophil gelatinase-associated lipocalin is instrumental in the pathogenesis of antibody-mediated nephritis in mice. Arthritis Rheum. 2012; 64:1620-31. doi: 10.1002/art.33485.

21. Suzuki M, Wiers KM, Klein-Gitelman MS, Haines KA, Olson J, Onel KB, et al. Neutrophil gelatinase-associated lipocalin as a biomarker of disease activity in pediatric lupus nephritis. Pediatr Nephrol. 2008;23:403-12. doi: 10.1007/s00467-007-0685-x.

22. Ahlawat RS, Batra V, Pendharkar S. Urinary TWEAK and NGAL as a biomarker of lupus nephritis activity. J Assoc Physicians India. 2016;64:69.

23. Gómez-Puerta JA, Ortiz-Reyes B, Urrego T, VanegasGarcía AL, Muñoz CH, González LA, et al. Urinary neutrophil gelatinase-associated lipocalin and monocyte chemoattractant protein 1 as biomarkers for lupus nephritis in Colombian SLE patients. Lupus. 2018;27: 637-646. doi: 10.1177/0961203317738226.

24. El Shahawy MS, Hemida MH, Abdel-Hafez HA, El-Baz TZ, Lotfy AM, Emran TM. Urinary neutrophil gelatinaseassociated lipocalin as a marker for disease activity in lupus nephritis. Scand J Clin Lab Invest. 2018;78:264-268. doi: 10.1080/00365513.2018.1449242.

25. Smith EM, Jorgensen AL, Midgley A, Oni L, Goilav B, Putterman $\mathrm{C}$, et al. International validation of a urinary biomarker panel for identification of active lupus nephritis in children. Pediatr Nephrol. 2017;32:283-295. doi: 10.1007/ s00467-016-3485-3.

26. Fang YG, Chen NN, Cheng YB, Sun SJ, Li HX, Sun $\mathrm{F}$, et al. Urinary neutrophil gelatinase-associated lipocalin for diagnosis and estimating activity in lupus nephritis: a meta-analysis. Lupus. 2015;24:1529-39. doi: 10.1177/0961203315600244.

27. Torres-Salido MT, Cortés-Hernández J, Vidal X, Pedrosa A, Vilardell-Tarrés M, Ordi-Ros J. Neutrophil gelatinaseassociated lipocalin as a biomarker for lupus nephritis. Nephrol Dial Transplant. 2014;29:1740-9. doi: 10.1093/ndt/ gfu062.

28. Hammad A, Mosaad Y, Elhanbly S, Youssef H, El Refaaey A, Elhusseini F, et al. Urinary neutrophil gelatinase-associated lipocalin as a marker of severe lupus nephritis in children. Lupus. 2013;22:486-91. doi: 10.1177/0961203313479419.

29. Yang CC, Hsieh SC, Li KJ, Wu CH, Lu MC, Tsai CY, et al. Urinary neutrophil gelatinase-associated lipocalin is a potential biomarker for renal damage in patients with systemic lupus erythematosus. J Biomed Biotechnol. 2012;2012:759313. doi: 10.1155/2012/759313.

30. Killock D. Lupus nephritis: NGAL: not just an innocent bystander? Nat Rev Rheumatol. 2011;8:3. doi: 10.1038/ nrrheum.2011.192.

31. Satirapoj B, Kitiyakara C, Leelahavanichkul A, Avihingsanon Y, Supasyndh O. Urine neutrophil gelatinase-associated lipocalin to predict renal response after induction therapy in active lupus nephritis. BMC Nephrol. 2017;18:263. doi: 10.1186/s12882-017-0678-3.

32. Jafari-Nakhjavani MR, Abedi-Azar S, Nejati B .Correlation of plasma interleukin-18 concentration and severity of renal involvement and disease activity in systemic lupus erythematosus. J Nephropathol. 2016;5:28-33. doi: 10.15171/jnp.2016.05.

33. Rubinstein T, Pitashny M, Levine B, Schwartz N, Schwartzman J, Weinstein E, et al. Urinary neutrophil gelatinase-associated lipocalin as a novel biomarker for disease activity in lupus nephritis. Rheumatology. 2010;49:960-71. doi: 10.1093/rheumatology/kep468.

34. Pitashny M, Schwartz N, Qing X, Hojaili B, Aranow C, Mackay $M$, et al. Urinary lipocalin-2 is associated with renal disease activity in human lupus nephritis. Arthritis Rheum. 2007;56:1894-903. doi: 10.1002/art.22594.

35. Tawfik Y, Shaat RM, El-Bassiony SR, Hawas S, Effat N. Urinary and serum neutrophil gelatinase-associated lipocalin as a biomarker in Egyptian systemic lupus erythematosus patients: Relation to lupus nephritis and disease activity. The Egyptian Rheumatologist. 2015;37:S25-S31. doi: 10.1016/j.ejr.2015.09.003.

36. Kiani AN, Wu T, Fang H, Zhou XJ, Ahn CW, Magder LS, et al. Urinary vascular cell adhesion molecule, but not neutrophil gelatinase-associated lipocalin, is associated with lupus nephritis. J Rheumatol. 2012;39:1231-7. doi: 10.3899/jrheum.111470.

37. Brunner HI, Bennett MR, Mina R, Suzuki M, Petri M, Kiani AN, et al. Non-invasive renal protein biomarkers are associated with histological features of lupus nephritis. Arthritis Rheum. 2012;64:2687-2697. doi: 10.1002/ art.34426.

38. Gwira JA, Wei F, Ishibe S, Ueland JM, Barasch J, Cantley LG. Expression of neutrophil gelatinase-associated lipocalin regulates epithelial morphogenesis in vitro. J Biol Chem. 2005;280:7875-82. doi: 10.1074/jbc.M413192200.

Copyright (c) 2019 The Author(s); Published by Nickan Research Institute. This is an open-access article distributed under the terms of the Creative Commons Attribution License (http://creativecommons.org/licenses/by/4.0), which permits unrestricted use, distribution, and reproduction in any medium, provided the original work is properly cited. 